\title{
The Arrested Development of Golden Rice: The Scientific and Social Challenges of a Transgenic Biofortified Crop
}

\author{
Hyejin Lee ${ }^{1} \&$ Sheldon Krimsky ${ }^{1}$ \\ ${ }^{1}$ Department of Urban \& Environmental Policy \& Planning, Tufts University, Medford, MA, U.S.A. \\ Correspondence: Sheldon Krimsky, Department of Urban \& Environmental Policy \& Planning, Tufts University, 97 \\ Talbot Avenue, Medford, MA, 02155, U.S.A.
}

Received: October 11, 2016

Accepted: October 18, 2016

Available online: October 24, 2016

doi:10.11114/ijsss.v4i11.1918

URL: http://dx.doi.org/10.11114/ijsss.v4i11.1918

\begin{abstract}
Since its initiation to reduce the global public health crisis of vitamin A deficiency (VAD), the Golden Rice (GR) Project has met with both successes and challenges. After 16 years of its scientific breakthrough in 2000 with the GR prototype to produce $\beta$-carotene in rice grain, it has yet to be released. As the first biofortified crop developed with transgenic technologies designed to reduce the micronutrient deficiency, GR has met controversy and even academic scandal. This review updates the science and situates GR in its political, regulatory and economic contexts. In doing so, peer-reviewed journal articles on GR and VAD were studied, specific data were cited from well-recognized organizations, and both the science and regulatory issues were checked through personal communications. This review aims not only to update and provide evidence-based analysis of GR, but also to facilitate broader social conversations on transgenic crops.
\end{abstract}

Keywords: Golden Rice, vitamin A deficiency, biofortification, transgenic crops

\section{Introduction}

On July 31, 2000 Time Magazine's front cover pictured plant scientist Ingo Potrykus, a professor at the Swiss Federal Institute of Technology, in a field with his new strain of rice with the headline "This rice could save a million kids a year" (Nash, Zurich Monday, \& Potrykus, 2000 July). This article described Potrykus' dream of creating carotene-enriched rice that would save countless Third World children from blindness and death. A dozen years later in August 2012, Greenpeace International voiced alarm at a scientific publication that had fed genetically engineered (GE) rice to 24 Chinese children aged 6 to 8 years (Greenpeace International, 2012 September 5). Greenpeace claimed that the study, supported by the United States Department of Agriculture, could not have been conducted without a breach of scientific and medical ethics. A campaigner at Greenpeace East Asia, responding to this news, said "It is incredibly disturbing to think that an American research body used Chinese children as guinea pigs for GE food, despite a clear directive against this experiment issued by Chinese authorities in 2008" (Greenpeace International, 2012 September 5).

The publication referred to by Greenpeace was a study that evaluated bioconversion efficiency of $\beta$-carotene to vitamin A from GE rice in children (Tang et al., 2012). The study, published in the American Journal of Clinical Nutrition in 2012 , concluded that $\beta$-carotene in GE rice was as effective as pure $\beta$-carotene in oil and better than that in spinach at providing vitamin A to children (Tang et al., 2012). While media firestorms (Hvistendahl \& Enserink, 2012 September 11) and contentious debates over GE rice continued, suspicions were raised that scientific institutions became vulnerable to anti-GE crop bias (Dubock, 2014). Quite unexpectedly, on July 292015 the publisher retracted the article and gave three reasons (American Journal of Clinical Nutrition, 2015). First, the authors failed to provide sufficient evidence that the study had been approved by a local ethics committee in China in a manner fully consistent with National Institutes of Health guidelines. Second, they failed to substantiate the full consent of parents of the children involved in the study through documentary evidence. Third, specific eligibility issues were questioned for two subjects in the study. Additionally, Tufts University, the affiliated institution of the principal investigator, issued a statement that the research failed to meet full compliance with the university's Institutional Review Board and the federal regulations, while affirming that the study data were validated and no health or safety concerns were identified (Enserink, 2013 September 18).

The GE rice in this study, also called Golden Rice (GR), was one of the rice (Oryza sativa) varieties under development. 
GR is the generic name given to GE rice that produces $\beta$-carotene or pro-vitamin A in rice endosperm (Al-Babili \& Beyer, 2005). This name is derived from the yellow color of the grain that is visible after milling and polishing, the procedure routinely employed to remove the outer grain layers (Al-Babili \& Beyer, 2005).

The GR project was launched and initially funded by the Rockefeller Foundation to alleviate VAD (Golden Rice Humanitarian Board [GRHB], n.d. a), which has been a major global health problem (Al-Babili \& Beyer, 2005). Its aim was to complement more traditional VAD interventions such as supplementation and industrial food fortification. Collaborating with Peter Beyer of the University of Freiburg, Potrykus was one of the GR inventors and also serves as the chairman of the Golden Rice Humanitarian Board, as of October 2016 (GRHB, n.d. b). In the 1990s Potrykus proposed the project to genetically engineer the pro-vitamin A pathway in rice (Potrykus, 2001). In 2000 when the first scientific breakthrough with the GR prototype was published in the journal Science (Ye et al., 2000), media reception of GR seemed very welcoming as expressed in the Time Magazine cover story (Nash et al., 2000 July) and a New York Times report, which anticipated its commercial release in two or three years (Christensen, 2000 Nov 21). There also were opposing voices from organizations such as Greenpeace arguing that GR is a genetically engineered product with potential risks (Cotter, 2013 October). After 16 years amidst all those debates and media attention to GR, it has yet to be either released or rejected. Currently, the International Rice Research Institute (IRRI), headquartered at Los Baños in the Philippines, serves as the coordinating institution for the GR project and has been working to commercialize GR varieties with its national partners (Philippines, Indonesia and Bangladesh) (International Rice Research Institute [IRRI], n.d. a) by backcrossing the selected transgenic event GR2-E into local varieties such as PSBRc82 and BRRIdhan29 (Department of Science and Technology-Biosafety Committee, 2015 Feb ; National Academies of Sciences Engineering and Medicine [NASEM], 2016).

The main objectives of this review, thus, are to update the science and current status of GR in the social, regulatory and economic contexts and in relation to VAD alleviation. The key questions are: what do existing peer-reviewed journal articles state about effectiveness and efficacy of GR?; what obstacles has the GR project met?; what arguments are made by skeptics of GR?; and what implications does the GR project, as a humanitarian aid, have for transgenic crop development overall? We shall begin with a review of the current trends of VAD and coping strategies.

\section{Current Situation of Vitamin A Deficiency and Coping Strategies}

Vitamin A deficiency is caused by a habitual diet that provides insufficient bioavailable vitamin A to meet physiologic needs. Rapid growth and frequent infections, which cause ineffective utilization of the vitamin, are also critical factors of VAD (Wambugu et al., 2015). The prevalence of VAD across low and middle-income countries has generally declined over time (G. A. Stevens et al., 2015). In 1991, 39\% of children aged 6-59 months in these countries were vitamin A deficient while VAD fell to 29\% in 2013. In East and Southeast Asia and Oceania, VAD drastically declined from $42 \%$ to 6\%, and in Latin America and the Caribbean from 21\% to 11\%. However in South Asia and Sub-Saharan Africa, it still remains considerably high and little has changed in these regions during the past two decades. For example, in 2013, the prevalence of VAD was $44 \%$ and $48 \%$ in South Asia and Sub-Saharan Africa, respectively. Also, more than $95 \%$ of VAD-related deaths occurred in those two regions (G. A. Stevens et al., 2015).

Hypotheses as to why the prevalence remains significantly high in South Asia and Sub-Saharan Africa include the limited effect of vitamin A capsule delivered with serum retinol, unsuccessful food fortification, insufficient dietary diversification or combinations of all or some of these (G. A. Stevens et al., 2015). Additionally, as frequent exposures to infections can increase the risk of subclinical deficiency (Walker et al., 2013) and decrease serum retinol concentrations in children with adequate liver stores, they might have contributed to persistent VAD in the regions with high infection burden (Stephensen, 2001).

To deal with the widespread VAD, three approaches have been implemented; a short-term supplementation, mid-term fortification and long-term dietary modification. The short-term solution involves the provision of high-dose vitamin A capsules with 100,000 or 200,000 International Units (IU) based on the age of children at 6-month intervals (World Health Organization, 2011). Substantial reductions in child mortality resulting from initial trials of vitamin A supplementation (VAS) led to efforts to scale up high-dose VAS, despite controversy on their actual benefits (G. A. Stevens et al., 2015). According to the United Nations Children's Fund, 69\% of children aged 6-59 months in 82 priority countries received VAS with effective two annual high-doses in 2014 (United Nations Children's Fund, 2016). Whereas, in the late 1990s, only half received the supplementation and less than $20 \%$ received two doses per year (G. A. Stevens et al., 2015). Despite these efforts, the prevalence of VAD has not improved in South Asia and Sub-Saharan Africa. This high-dose VAS, nevertheless, is the most widely utilized intervention but the least likely long-term solution. Additional approaches involve a continuous supplementation with low-dose vitamin A in products such as micronutrient powders and small-quantity lipid-based nutrient supplements (Tanumihardjo, Mokhtar, Haskell, \& Brown, 2016). The mid-term food fortification and long-term dietary modification for vulnerable groups are considered more sustainable (Berman et 
al., 2013). Fortification of common foods with vitamin A such as cooking oil, table sugar, cereal flour, or dairy products can be a cost-effective intervention (Berman et al., 2013). However, as this method requires appropriate food vehicles and sufficiently developed food industry (Tanumihardjo et al., 2016), it is more difficult to establish in developing countries especially in poor rural regions with little infrastructure and educational effort (De Steur et al., 2014). The long-term approaches to reduce VAD include strategies with agricultural interventions and dietary modification to increase production, availability, accessibility, and consumption of vitamin A rich foods.

Among these strategies, biofortification has received considerable attention as a valid alternative for an agriculture-based strategy to alleviate the burden of micronutrient malnutrition (De Steur et al., 2014). In section 3, biofortification with rice as its substrate will be discussed.

\section{Biofortification of Transgenic Rice to Combat Vitamin A Deficiency}

Biofortification is an umbrella term for a diverse range of projects and possibilities (Brooks, 2013). It is best understood on three levels; first as a range of technologies for developing micronutrient-dense crops, second a development intervention to improve public health, and third an idea that links agriculture, nutrition and health in a particular way (Brooks, 2013). For the VAD relevant discussions, its definition will be narrowed as enhancement of micronutrient contents of staple crops through conventional or transgenic breeding techniques (De Steur et al., 2012).

To successfully combat micronutrient deficiency through biofortification, choosing the right food sources is critical (De Steur et al., 2012). In principle, a staple crop such as rice, maize or potato should be selected to reach populations that may be the most vulnerable to inadequate levels of micronutrient intakes. Equally important is deployment of biofortified crops in a supportive geographical context. For instance, rice would be suitable in Asia whereas maize would be preferable in Africa (Berman et al., 2013).

As mentioned, biofortification can be achieved with conventional breeding or GE technology. Conventional breeding, however, has limited options compared to GE because it is only possible with closely related or sexually compatible plants, thus relying on natural variations in target crops (De Steur et al., 2015). Even if possible it would take a considerable amount of time to produce a biofortified crop through mutagenesis. Although marker-assisted breeding and quantitative trait loci mapping can aid and accelerate conventional breeding, the estimated minimum numbers of generations for clonally propagated crops such as potato are 7 generations, 9 for self-fertilizing crops such as rice, and 17 for cross-fertilizing crops such as maize (Shimelis \& Laing, 2012).

Before the discussion of the GE biofortification option, it is useful to distinguish among three generations for GE crop development. The first generation involved agricultural production traits, such as insect or herbicide resistance. The second generation of GE plants contained enhanced nutritional contents (Zilberman \& Wesseler, 2014), including value-added innovations (Kowalski \& Kryder, 2002). And the third generation of transgenic plants focuses on the production of industrial chemicals and pharmaceuticals (Zilberman \& Wesseler, 2014). Of the three, the second generation with modified output traits can directly increase levels of key vitamins in many crops compared to conventional varieties (Berman et al., 2013). Despite the prevalence of GE-derived crop traits, there have been continuing intense debates over GE applications, especially as a strategic approach to reduce malnutrition.

The proponents of GE emphasize its potential to increase effective yields, combat hunger and poverty, promote sustainable agriculture, make a positive impact on human nutrition and health, and strengthen positions of poor and small-scale farmers. The opponents, on the other hand, criticize its potential to threaten human and animal health through toxins or allergens in GE crops, cause build-ups of antibiotic resistance, erode biodiversity and ecosystem health through vertical or horizontal gene flows, create new reliance of poor farmers on seed and food supply, oversimplify hunger and poverty issues, override the sovereignty of developing countries and diminish freedom of choice for farmers and consumers (Stein, Sachdev, \& Qaim, 2006). In a news release issued September 5 2012, Greenpeace wrote: “'Golden rice' is an irresponsible and dangerous way to address Vitamin A Deficiency (VAD). 'Golden rice' does not address the underlying causes of VAD, which are mainly poverty and the lack of access to a more diverse diet. Because it encourages a diet based on one staple rather than an increase in access to the many vitamin-rich vegetables 'golden rice' could, if introduced on a large scale, exacerbate malnutrition and ultimately undermine food security" (Greenpeace International, 2012 September 5).

Amidst all the controversies over plant biotechnology, rice has been genetically engineered as a food vehicle for biofortification. Rice is the second largest crop produced in the world only followed by maize (Fischer, Byerlee, \& Edmeades, 2014), but it is known to be low in micronutrients. With zinc, the HarvestPlus program has released a series of zinc-enhanced rice varieties through conventional breeding since 2013 with Bangladesh as its primary target country (HarvestPlus, 2015 August 5). However, application of conventional breeding has modest success in iron (Harjes et al., 2008) and less so for folate, and not achievable for vitamin A due to lack of genetic variability in rice and absence of vitamin A precursors in the rice endosperm (Ye et al., 2000). This constraint prompted the utilization of GE technology 
to develop vitamin A fortified rice, also known as Golden Rice. Section 4 explores how GE technology as a new form of molecular breeding was used for the development of rice fortified with vitamin A.

\section{Invention and Development of Golden Rice}

In places where green vegetables with an ample supply of micronutrients that can be turned into vitamin A were unavailable to local inhabitants due to crop seasonality (Harjes et al., 2008), expense and low bioavailability of green leafy plant carotenoids (Boileau, 1999), the use of a staple and relatively abundant crop to provide the sources of vitamin A was the goal behind Golden Rice. According to a report from IRRI "Because rice is widely produced and consumed, Golden Rice has the potential to reach many people, especially those missed by current interventions" (Abdullah \& Villegas, 2015 February 16-17). Of the 600 carotenoids found in nature, only three are important precursors of vitamin A, namely, $\alpha$-carotene, $\beta$-carotene and $\beta$-cryptoxanthin (Wambugu et al., 2015). In plants, vitamin A precursors occur in the form of $\alpha, \beta$ and $\gamma$-carotenes, and xanthophyll $\beta$-cryptoxanthin. The most vital of them is $\beta$-carotene because it is readily converted into retinol, which the human body can use to make vitamin A although conversion rates vary among plants (Wambugu et al., 2015).

All plant tissues that accumulate high levels of carotenoids have mechanisms for carotenoid sequestration. Rice, likewise, possesses the whole machinery to synthesize $\beta$-carotene (Al-Babili \& Beyer, 2005). However, while this process is fully active in leaves, part of it is inoperative in rice grain. The starch-rich endosperm of rice contains little lipid, and accumulation of high levels of carotenoids requires oil deposition (Al-Babili \& Beyer, 2005).

In 1993 Peter Beyer and Ingo Potrykus began investigating how $\beta$-carotene is produced in daffodils (Narcissus pseudonarcissus). They isolated the biochemical steps that make the flower yellow and discovered that they could produce the vitamin A precursor in rice by the addition of three genes, the plant psy gene from daffodil, the crti gene from the bacterium (Erwinia uredovora) and the selective marker hygromycin phosphotransferase (aphIV) gene. The genes as well as the entire $\beta$-carotene biosynthetic pathway were introduced into rice endosperm in a single transformation effort through an Agrobacterium vector. The vector $p B 19 h p c$ combined the sequences for the daffodil psy and bacterial crti placed under the control of endosperm-specific glutelin and constitutive cauliflower mosaic virus $35 \mathrm{~S}$ promoter. This transgene construct constituted as a plasmid was expected to direct the formation of lycopene in the endosperm plastids (Ye et al., 2000).

Pre-cultured immature rice embryos were inoculated with Agrobacterium, and hygromycin-resistance plants were analyzed for the presence of $p s y$ and $c r t i$ genes. The antibiotic marker, hygromycin-resistance, was later replaced by the phosphomannose isomerase (plant cells lacking the marker are unable to survive on a synthetic mannose-a sugar monomer medium) (Privalle, 2002) to avoid an antibiotic selection system which may slow a regulatory process (Hoa, Al-Babili, Schaub, Potrykus, \& Beyer, 2003). The maximum carotenoid level in the transgenic lines was $1.6 \mu \mathrm{g} / \mathrm{g}$, with about $50 \%$ of it as $\beta$-carotene (Ye et al., 2000). Although $0.8 \mu \mathrm{g} / \mathrm{g}$ of $\beta$-carotene was significantly higher than the level in white rice, it was unknown that this amount could make a meaningful dent on VAD. This allowed early critics of GR to diminish the results because children would have to consume unrealistic amounts of GR to achieve their recommended daily intakes of vitamin A equivalents (De Moura, Miloff, \& Boy, 2015). This study, nevertheless, provided the proof of concept that $\beta$-carotene could be produced in rice grain, also called the first generation of GR (Al-Babili \& Beyer, 2005).

Unknown at this stage however was whether and to what extent the $\beta$-carotene would convert into usable vitamin $A$ and prove bioavailable (Brooks, 2013). Furthermore, while japonica rice varieties were utilized for GR development, its target populations live where indica varieties are predominant. Therefore, transferring the $\beta$-carotene trait into indica varieties and ensuring stable trait expression became a critical issue (Brooks, 2013). Eventually, the GR trait was transferred to indica type cultivars; a study reported two transformed elite indica varieties, which were considered highly valuable because of projected prompt approval (Hoa et al., 2003).

The next logical approach to increase the $\beta$-carotene level in the first generation GR was to identify a rate-limiting step in the enzymatic pathway of the process and overcome it. This approach led to the development of the second generation GR (Al-Babili \& Beyer, 2005). Introduction of the maize (Zea mays) psy gene in place of one from the daffodil enabled the second generation GR to be developed under the hypothesis that the daffodil psy gene limited $\beta$-carotene accumulation (Paine et al., 2005). Through systematic testing, the psy gene from maize was identified to substantially increase $\beta$-carotene accumulation. The scheme used to generate the transgenic events involved the maize psy gene, bacterial crti gene, rice glutelin promoter, catalase gene from castor bean and a hygromycin-resistance marker. Subsequent analysis of the rice showed that the GR trait was stable and heritable. More importantly, a significant increase, up to 23 -fold in comparison to the first generation, in total carotenoids was observed with a maximum of 37 $\mu \mathrm{g} / \mathrm{g}$ of which $31 \mu \mathrm{g} / \mathrm{g}$ is $\beta$-carotene (Paine et al., 2005).

With the significant levels of pro-vitamin A equivalents, $50 \%$ of the vitamin A Recommended Dietary Allowance (RDA) 
or $300 \mu \mathrm{g}$ for children aged 12 to 36 months could be met with $72 \mathrm{~g}$ of dry GR. The estimate was based on a $12: 1$ conversion factor of $\beta$-carotene to vitamin A. It appeared likely to meet vitamin A requirements given that a typical portion of rice for children is $60 \mathrm{~g}$ (Paine et al., 2005).

With these new $\beta$-carotene results, GR could now respond to severe VAD in India, Vietnam and Bangladesh whereas, in other countries, it may help reduce clinical or sub-clinical VAD-related diseases (Wesseler \& Zilberman, 2014). But its efficacy needed to be confirmed through human studies before its full potential could be realized. To determine the vitamin A value of dietary GR in humans, a study was conducted with human subjects (Tang et al., 2009). The study showed that $\beta$-carotene derived from GR was effectively converted to vitamin A with conversion factors ranging from 1.9:1 to $6.4: 1$ by weight. Using the mean conversion factor of $3.8: 1$ as in $3.8 \pm 1.7$ (mean \pm standard deviation), the research predicted that $100 \mathrm{~g}$ of uncooked GR would provide $55 \%$ to $70 \%$ of RDA for men and women. In their analysis, the total amount of GR $\beta$-carotene was the same before and after it was cooked.

However, some scientists surmised that the new synthetic pathways enabled by the gene insertion can produce potential toxic by-products (Schubert, 2008) while dietary $\beta$-carotene itself is generally considered a safe source of vitamin A (Novotny et al., 2010). Plant carotenoids can yield a family of retinoid compounds, including retinol, retinal and retinoic acid. While critical for their biological functions, all retinoids and their derivatives, according to Schubert, are likely teratogenic to humans. GR with its increased level of $\beta$-carotene synthesis might have potential to accumulate harmful compounds similar to retinoids. Although a research study concluded that $\beta$-carotene from maize could avoid the potential for hyper-vitaminosis A observed with preformed vitamin A supplementation and fortification (Gannon et al., 2014), biologically active compounds derived from the GR carotenoid synthesis, according to Schubert, could still have negative effects on human health (Schubert, 2008).

As GE technology made GR invention possible, the intellectual property (IP) rights associated with the GE technology involved competing stakeholders in its potential development of a product. Section 5 briefly examines IP rights with GR.

\section{Intellectual Property Rights of Golden Rice}

Each 3-year sequential funding by the two organizations, the Rockefeller Foundation and European Community, enabled GR development to be achievable (Paine et al., 2005). Although funding from the Rockefeller Foundation was free of obligations, financial backing from the European Community required the participation of an industrial partner that would hold rights to inventions developed during the research. This funding obligation, thus, formed the legal status of GR as a two-track system, one being noncommercial humanitarian and the other commercial. Zeneca, which later merged with Novartis ${ }^{\circledR}$ to form Syngenta ${ }^{\circledR}$, became the industrial partner (Beyer et al., 2002). The GR inventors assigned their exclusive technology rights to Syngenta ${ }^{\circledR}$ to receive in turn a humanitarian license with the sublicensing right to public research institutions and low-income farmers in developing countries (Kowalski, 2015). The two-track IP management and licensing strategy, according to Kowalski (2015), was innovative.

The humanitarian license covers GR technology applied to public germplasm in countries defined by the Food and Agriculture Organization of the United Nations as low-income and food-deficit, and to the resource-poor farmers earning less than US \$10,000 per year (GRHB, n.d. c). Most notably, the license allows reuse of the harvested GR seed for the following seasons, which indicates the farmer's ownership of GR seed unlike commercial ventures. Currently, the license is granted to public entities in Bangladesh, the Philippines, China, India, Indonesia, and Vietnam (Kowalski, 2015). Thus, eventual introgression of the GR trait would be expected into local rice varieties grown and consumed in these VAD-affected areas.

In the contexts of the Freedom-to-Operate, IP management, and licensing, GR promoters offer a few narratives for successful development. First, despite the early concerns, IP rights did not delay introduction of GR into developing countries with endemic VAD. Instead, safety and regulatory issues have largely driven the delays which will be covered in a later section. Second, by strategically assigning their GR IP rights to Syngenta ${ }^{\circledR}$ as a key IP manager, the inventors enabled the GR projects to accelerate access to other integral technologies owned by Syngenta ${ }^{\circledR}$ or other entities. This facilitated the humanitarian licensing to public research institutions for GR transfer in developing countries.

First, the strategic public-private-partnership (PPP) is deemed exemplary because clearly defined expertise and specific roles allowed and facilitated global access to GR through the established managerial and marketing structures. Second, it illustrates the importance of proactive IP management, which includes access to patent information, and ability to analyze and categorize patent data for accelerated delivery of innovations in agricultural biotechnology. Third, the involvement of developing countries came significantly later. It was not until after the earlier steps of identifying potential IP constraints that strategies were created to overcome the constraints, and organizational capacity was developed to move GR further forward. These steps were mostly carried out by parties in the developed countries, including Syngenta $^{\circledR}$, the International Service for the Acquisition of Agri-Biotech Applications, and the members of 
GRHB. Hence, building a system that ensures early involvement of beneficiaries should be prioritized. Fourth, a paradigm shift is needed for developing countries to realize full potential of agricultural innovation such as GR. It entails moving from being passive recipients of aid towards becoming active drivers of GR trait identification, access, and adoption. This requires investment in building human capital, global networks, and institutional infrastructure to establish research collaborations, material transfer agreements and PPP (Kowalski, 2015).

Although issues over IP rights appear to have been worked out, they have yet to be tested and proven under actual market conditions. For instance, GR might be stacked with commercially patented traits such as herbicide and disease resistance or other micronutrients. As important an issue as licensing and patenting are to the business communities, there are still questions about GR's actual contribution to health and economies. Therefore, benefits from GR adoption should be appropriately addressed in economic terms. Section 6 reviews estimates on its health benefits and cost-effectiveness mainly in India, Bangladesh and China.

\section{Health Benefits and Cost-Effectiveness of Golden Rice}

The 2012 Copenhagen Consensus reemphasized addressing VAD and zinc deficiency as the most serious issue in developing countries for economic development since malnutrition affects labor productivity and human capital accumulation (Wesseler \& Zilberman, 2014). Estimates of benefits and cost-effectiveness of better nutrition can be measured with the disability-adjusted life year (DALY) framework (Wesseler \& Zilberman, 2014). The World Bank and United Nations World Health Organization (WHO) have applied the DALY framework to measure the health gap in developing countries (De Steur et al., 2012), since the global burden of disease study in 1996 (Murray \& Lopez, 1996). The framework also became the standard evaluation tool for estimating the burden of micronutrient malnutrition and cost-effectiveness of related interventions (De Steur et al., 2012). This method describes both mortality and disability-weighted morbidity of a health condition in a single index, expressed in terms of the number of DALYs lost (De Steur et al., 2012). Moreover, the World Bank proposed analysis methods for the cost-effective interventions in international dollars considering the relevant contexts such as the disease burden or budget of the setting in question (Marseille, Larson, Kazi, Kahn, \& Rosen, 2015).

In India, a study attempted to estimate the second generation GR life-cycle effects from its cultivation through health impacts with a model and national data set of household food consumption (Stein et al., 2006). The study showed that 2.3 million DALYs were lost and that India's annual burden of VAD could be reduced by $59.4 \%$ under optimistic assumptions. In other words, 1.4 million healthy life years could be saved each year if GR were to be widely consumed. In a low impact scenario with less GR consumption and pro-vitamin A production in GR, the burden of VAD could be reduced by $8.8 \%$. In both scenarios, the cost per DALY saved through GR ranged between US $\$ 3.06$ and US $\$ 19.40$, which were lower than the current supplementation efforts and outperformed the international cost-effectiveness thresholds (Stein et al., 2006). The study, therefore, recommended that GR should be a complementary intervention to lessen VAD in rice-consuming populations as a medium-term tool (Stein et al., 2006).

In Bangladesh, a study explored the net benefits of GR assuming the annual amount of DALYs averted depends on GR coverage rates (Deb, 2016). The population acquires about $70 \%$ of its calorie intake from rice. According to the study, each $1 \%$ increase in GR coverage reduced annual VAD-related DALYs by 251 DALYs. In the optimistic scenario this benefit equals US $\$ 40$ million at the 5\% level while the equivalent value for the conservative scenario is US \$25 million. Additionally, it estimated that each taka (Bangladesh currency) spent on GR could generate 416 takas of health benefits. Therefore, the author concluded the current research with the GR cultivar of the popular rice strain of Bangladesh (GR-2 E BRRIdhan29) should receive political supports while being monitored for GE effects on human health and the environment (Deb, 2016). Also, De Moura et al. (2016) analyzed Bangladeshi data to simulate changes in VAD if GR were consumed. The substitution of GR for white rice in their most optimistic scenario reduced the prevalence of vitamin A inadequacy from $93 \%$ at baseline down to $20 \%$ and $13 \%$ among children and women, respectively. However, it should be mentioned that simulated decreases in vitamin A inadequacy largely varied depending on GR substitution rates which ranged from $10 \%$ to $70 \%$, and $\beta$-carotene levels from 0 ppm to $20 \mathrm{ppm}$ (De Moura et al., 2016).

China is the world's largest rice producer and one of the first countries that issued a biosafety certificate for GE insect resistant rice although requiring additional production trials before full commercialization began (De Steur et al., 2012; Waltz, 2010). Its favorable stance and support for biotechnology enabled China's increasing investments in GE rice as well as biofortified staples (De Steur et al., 2012). One study assessed the overall burden of VAD in China at 1,991,120 DALYs lost per year (De Steur et al., 2012). An estimate of cost-effectiveness per DALY saved from pro-vitamin A biofortification came to be US $\$ 5$ and US $\$ 18.1$ under optimistic and pessimistic circumstances, respectively (De Steur et al., 2012). However, the study cautiously pointed out that in many developing countries where multiple micronutrient deficiencies are a challenging issue, introducing several biofortified crops or varieties with a single micronutrient trait might not be appropriate. The concern was that each micronutrient trait would achieve only a limited coverage with 
biofortified crops and varieties competing with one another. Additionally, the cost estimates should be taken with caution because the study relied on several key assumptions. For instance, China has recently reduced malnutrition through overall poverty reduction and targeted micronutrient interventions. If such progress continues, the health burden of micronutrient deficiencies will decrease. This in turn could potentially contribute to the overestimated cost-effectiveness of biofortification (De Steur et al., 2012).

With the promising results from cost-effectiveness analysis, properly managed IP rights and scientifically proven efficacy, GR release could be well anticipated. However, even in India where a perceived cost from the delayed GR approval could be as high as US $\$ 199$ million per year (Wesseler \& Zilberman, 2014), it is still unavailable. A GR proponent described its regulatory situation as "intransigent opposition has provided already risk-averse regulators with the political cover to adopt an overly precautionary approach" (Miller \& Kershen, 2013). In section 7, reasons and hypotheses for the delayed GR release will be explored along with regulatory clearance issues.

\section{Golden Rice in Regulatory Limbo for Release}

As of August 2016, screen-house and confined field trials of GR are being conducted by IRRI and the Philippine Rice Research Institute (PhilRice), following biosafety and other regulatory protocols. Similar activities are ongoing in Bangladesh with its local varieties, where biosafety data are being generated as required by regulatory agencies (IRRI, n.d.). It is uncertain at this stage when GR release is planned by IRRI.

Currently approved GE crops are products with improved agronomic traits that mainly benefit farmers (De Steur et al., 2012). Despite the international growth in the first generation of GE crops, there has been a global regulatory slowdown in approval of new transgenic crops as agricultural biotechnology remains politically controversial in Europe and elsewhere (De Steur et al., 2015). As a second generation GE crop, GR is considered by some to be the most advanced biofortified GE crop thus far in development and most likely the first to be released (De Steur et al., 2015). Therefore, GR may illustrate the challenges biofortified GE crops will face in the path toward commercialization despite the claims for its enhanced nutritional qualities and benefits. Among the factors that could affect GR release are consumer resistance due to its yellow color, producer reluctance to adopt GR, vitamin A stability with various culinary methods and storage, and potential changes in current rice consumption patterns in target populations. Also, some developing countries have limited capacity to conduct localized research owing to substantial upfront investment (Berman et al., 2013). However, the most evident barriers to its commercialization are the regulatory process and approval for protocols, which also require additional funding (Berman et al., 2013). The national regulatory requirements of the Philippines and other countries are based on the international guidelines and procedures for the safe use of GE including the Codex Alimentarius, the Organization for Economic Co-operation and Development Consensus Documents, and the Cartagena Biosafety Protocol (IRRI, n.d. b).

One of the GR inventors, Ingo Potrykus, detailed and criticized the eight regulatory clearance steps for the delayed GR release (Potrykus, 2010). First, national regulatory authorities advise under public scrutiny that antibiotic selectable marker genes be deleted. Although he argued that the usage of antibiotic marker genes is proven harmless, the safety issue still remains controversial and inconclusive. Second, regulatory authorities do not accept complicated integration of transgenes because of any potential unforeseeable consequences. GR utilized Agrobacterium-mediated transformation, which does not guarantee clean integration, i.e., integration of the engineered sequence without additional and multiple copies. Potrykus pointed out that even though a traditional breeding process may lead to uncontrolled integration with mutagenesis, such random mutagenesis goes unregulated. Third, approval of GR requires regulatory clean events, meaning integration of no additional sequences and only one copy of the transgene (I. Potrykus, personal communication, May 18,2016), which make them unproblematic for regulatory authorities in all molecular genetic aspects. The transgene is integrated in an ideally clean manner when there is only one copy of it, no alterations of the construct, no read-through on both sides, no disturbance of existing reading frames, no activation or inactivation of neighboring genes or expression signals, no activation of possible mobile elements, and stable expression at the predicted level and under the predicted conditions. Though technically feasible, he argued, it entails excessive efforts and resources. Fourth, regulations for the trans-boundary movement of seeds set by the Cartagena Protocol are another source of regulatory delay. According to the inventor, it took over two years to transfer breeding seed from the Philippines to Vietnam and a year from the United States to India. As GR is an international project involving rice breeders in different countries, he insisted that this international collaboration should allow free exchange of breeding materials among countries. Fifth, regulation requires a specific sequence of test procedures that must be followed before field tests, including growth chamber, greenhouse, screen-house (screening procedures), and finally field tests. This sequence, Potrykus noted, means that GR tests can begin on small plots after 18 months. Also, granting permission for a test could arguably be a political matter. He mentioned that while awaiting permission for small plot tests in developing countries, GR was approved for field testing by the United States within a 6 month period in 2004. Furthermore, he stressed that the mandatory sequence prior to the field test does not consider the nature of breeding because it requires 
large numbers of offspring under different conditions, which may involve some sequence modification. Sixth, the requirement for one transformation event selection became a significant regulatory hurdle. His argument is that preparing a regulatory dossier for a single transgenic event can be as expensive as US \$35 million and that it is impractical to deregulate several independent transgenic events (I. Potrykus, personal communication, May 18, 2016). This forces GE crop developers to base all variety development on a single transgenic event. Selecting a single event and then investing all resources in it may require a collection of numerous data from many events. This extensive data collection, he reasoned, is improbable without extended field work, and event selection can only be possible with permission for field experiments. Seventh, he argued that the required regulatory dossier can be prohibitively costly and time-consuming for GR, since it has already taken at least four years. Lastly, once a complete regulatory dossier is assembled, the actual procedure for regulatory clearance probably takes less than a year. Therefore, the inventor argued, neither the regulatory authorities nor the final regulatory step is responsible for the delayed registration of GR varieties. In his conclusion, the above-mentioned rules and regulations apply an extremely precautionary approach to GR, which Potrykus attributes to political considerations (Potrykus, 2010).

Nevertheless, the regulatory barriers are not the sole issue of GR commercialization. The ultimate success of GR will depend on its wide acceptance for production and consumption, and on willingness to pay (WTP). Section 8 examines public perceptions of GR with relevant concerns of WTP for a premium of biofortified rice.

\section{Consumer Perceptions of Golden Rice}

Although an increasing number of studies report successful biofortifications in the laboratory, this second generation of GE crops remains mostly unavailable to consumers, largely due to the regulatory process (De Steur et al., 2015). However, the current regulatory barriers aside, the question should be: will consumers purchase and consume GR as its developers seem to assume favorable market acceptance?

Generally, consumers tend to be more willing to pay premiums for non-GE foods in comparison to the first generation GE foods (Lusk, Jamal, Kurlander, Roucan, \& Taulman, 2005). However, when direct benefits such as increased nutrients were added to the GE foods and they were compared, the premiums for non-GM counterparts decreased by $49 \%$ (Lusk et al., 2005). This indirectly implies improved consumer perception of GE biofortified crops over non-GE counterparts. Yet more directly, a study found that premium payments for GE biofortified crops ranged from $20 \%$ to $70 \%$ across targeted crops, micronutrients, and countries (De Steur et al., 2015). Nonetheless, rice might be different because rice-consuming societies are known for their rich biocultural diversity around this staple crop (Brooks, 2013). Thus, the question should be; will farmers and consumers choose GR over a range of local and traditional varieties, readily available and adopted for their farming practices?

The only GR characteristic visibly different from other rice varieties is its yellow color in polished grain. To promote GR, rice dishes such as pilau rice, popular in parts of South Asia are used as an example because the rice dish uses spices which lend a yellow hue to cooked rice. The proponents of GR indicate that yellow rice, therefore, may be accepted to rice consumers across South Asia. However, in the case of uncooked rice, the yellow color conveys presence of mold, indicative of severely reduced quality. Thus, the challenges to generate preference for GR would not be insignificant (Brooks, 2013).

Other than the color-related issues, there have been efforts to measure consumer acceptance as WTP for GR. As none of the GE biofortified crops are currently approved for consumption, much research determines ex ante their potential demand with estimated consumer WTP (De Steur et al., 2014). Overall, consumers in the Philippines, India and the United States, depending on the survey methods applied, were willing to pay $40 \%$ (Depositario, Nayga Jr, Wu, \& Laude, 2009), 19.5\% (Deodhar, Ganesh, \& Chern, 2008), and 16\% (Lusk, 2003) of a premium in each country, respectively for GR. Another study conducted in India concluded that a positive mean WTP for GR could indicate potential existence of GR markets in India (Kajale \& Becker, 2015). This study noted that consumers in developing countries would be more supportive of GE crops due to the food security issue, therefore perceiving GE crops as beneficial. However, several studies indicate that GR acceptance could be compromised if they do not resemble the conventional products (De Steur et al., 2014; Onyango \& Nayga Jr, 2004; Siegrist, 2008). The intensified yellow color of GR adversely affected its acceptability in Thailand and Bangladesh (Prom-u-thai, Rerkasem, Fukai, \& Huang, 2009). Similarly, the orange-colored pro-vitamin A biofortified maize were less preferred than unfortified white maize (De Steur et al., 2014). Although scientific evidence is still lacking, GE biofortification may also change sensory attributes which could reduce consumers' willingness to consume micronutrient-enriched crops. The aroma and taste of pro-vitamin A enriched maize, for example, was found undesirable in Mozambique (R. Stevens \& Winter-Nelson, 2008). Other potential changes in GR sensory quality in cooking may need further examination including the multiple ways in which rice and culture intertwine in diverse rice consuming societies.

Notwithstanding favorable projections for GR, there has been recurring opposition to it. The opposing side is often 
branded at least irresponsible and at most as committing a crime against humanity (Barklund \& Lindqvist, 2009). In section 9, the opposing views and their rationale behind GR rejection are reviewed.

\section{Opposing Viewpoints to Golden Rice}

Golden Rice has become one of the major targets of anti-GMO (genetically modified organism) groups as illustrated by Greenpeace activists, who destroyed GR field trials in the Philippines (Dash et al., 2016). A number of anti-GMO organizations, including Greenpeace, oppose GR for several reasons. According to their beliefs, allowing GR would open up the path for the entire GMO applications. They introduce the Trojan horse metaphor where GR is the vessel for all other GE crops. Also, they express fear that GR would promote monoculture and that real needs of farmers might be ignored. Another concern is that GR can impose adverse impacts on the cultivation of conventional and organic rice, which could harm rural livelihoods (Dash et al., 2016).

In the earlier years there was criticism of the poor expression of vitamin A in GR. Advances have improved carotene expression in the rice and thus the expression concern has become moot. There is still some debate about vitamin A efficacy due to the highly unsaturated structure of carotenoids (De Moura et al., 2015). This structure makes carotenoids susceptible to post-harvest degradation by heat, oxygen and light. De Moura et al. (2015) reported that retention levels of pro-vitamin A carotenoids in cassava, maize, and sweet potato show varied results depending on the post-harvest processing, cooking methods, and storage conditions and duration. The retention in maize, cassava and sweet potato, for instance, reached as low as 20\% after 1-4 months of storage. Several studies also showed a strong genotypic effect on the retention of pro-vitamin A carotenoids within the same crop (De Moura et al., 2015). A recent study attempted to improve carotenoids degradation in GR by manipulating the gene $r 9-L O X 1$ known for rice seed quality degradation (Gayen, Ali, Sarkar, Datta, \& Datta, 2015). By silencing the gene and consequently reducing the enzyme lipoxygenase (LOX) activity, the study showed that degradation of $\beta$-carotene was significantly different between GR lines ranging from $9.6 \%$ to $24.7 \%$ and the control rice $56 \%$. It, thus, concluded that decreasing the LOX activity could be an effective tool to reduce a post-harvest loss of $\beta$-carotene during storage (Gayen et al., 2015). However, it is a justifiable claim that degradation rates and patterns of the GR pro-vitamin A should be evaluated among different genotypes under diverse planting, harvesting, and storage conditions to ensure its high efficacy.

The question of whether GR will prove more effective in addressing VAD than other types of intervention is still open to question as well. A distinction should be made between effectiveness in a real-world context as compared to controlled laboratory or greenhouse conditions. Many children with VAD suffer from protein-energy malnutrition, and intestinal infections interfere with the absorption of $\beta$-carotene or its conversion to vitamin A. Perhaps most importantly, conversion of $\beta$-carotene to vitamin A depends notably on the presence of fats and proteins, the nutrients often deficient in the diets of target populations (Brooks, 2013). For instance, the conversion of GR $\beta$-carotene into retinol could theoretically vary from 3.5: 1; 6.5: 1; and 6.7: 1 with high fat, low fat and no fat diet, respectively (Grusak, 2005). Therefore, the minimal needs for dietary fat must be evaluated for absorption of the lipophilic carotenoids as the diets of the poor often tend to be low in oil and fat (Grusak, 2005). Thus, findings from studies with healthy children may not truly reflect the likely GR impact in malnourished populations.

The GR critics instead support the existing VAS, injection and fortification programs. They also emphasize the availability of natural sources of vitamin A from nontraditional fruits and vegetables, refined palm oil, sweet potato, cassava, mango, and papaya. GR critics point out that vitamin A capsule distribution is more effective because it can be subject to monitoring and evaluation for coverage and impact (Brooks, 2013). GR in national seed systems may not go through the same rigorous monitoring process with the debatable post-harvest stability of the GR $\beta$-carotene. Furthermore, rice systems are highly diverse and decentralized compared to other grains. In the Philippines, for example, rice milling is a local activity. While there are a few dominant facilities, an estimated 10,000 rice mills across the country are operating. Accordingly, monitoring all their outputs would be a tall order. A similar lesson was learned from the mandatory fortification of rice with vitamin B in the 1950s (Prom - u - thai et al., 2009). Therefore, the extent to which GR can effectively substitute for pharmaceutical supplementation or other interventions will depend on how such existing challenges are tackled (Brooks, 2013).

Lastly, GR critics argue that because the GR project has drained a large portion of rice research funds with little benefit realized, future research funds should support diversified approaches to address VAD (Krawinkel, 2007). In most cases, nutritional issues are complex. Krawinkel (2007) has argued that the real challenge is to solve these complex problems, not by reducing the problems to a single nutrient but by integrating existing approaches in the most efficient ways to reduce the DALYs caused by nutritional deficits and insecurity (Krawinkel, 2007). Section 10 addresses non-GR options available to reduce the scourge of VAD.

\section{Alternatives to Reduce Vitamin A Deficiency}

Present efforts to improve the VAD status focus on pharmaceutical supplementation and industrial food fortification 
(Stein, Sachdev, \& Qaim, 2008), yet there are other food-based approaches recommended to reduce VAD. First, promoting red and black rice landraces is suggested even though it entails additional breeding efforts due to their low yields. Such landraces contain up to $0.38 \mu \mathrm{g} / \mathrm{g}$ of $\beta$-carotene when not milled as the $\beta$-carotene is stored in the outer layers of the unmilled rice. In fact, this approach is similar to GR only without GE application. However, promoting these landraces would face the same issues as GR, requiring consumers to accept rice in a different hue. But most challengingly, it involves changes in their dietary and food preparation behaviors, in other words, asking them to prepare and consume unmilled rice. This approach may yield limited benefits. When their $\beta$-carotene content of $0.38 \mu \mathrm{g}$ with lower bioavailability is assumed, the landraces will reduce DALYs by $0.1 \%$ and $3.1 \%$ each in the low and high impact scenario, respectively. GR opponents such as Greenpeace endorse these landraces while heavily criticizing GR on the ground that the target population needs to consume a large amount of GR. To achieve the same vitamin A status as with GR consumption, much higher quantities of the colored landraces must be consumed. Hence, it seems reasonable to say that GR has faced opposition because of GE application, not simply because of the underlying rationale of increasing $\beta$-carotene production in a staple crop (Stein et al., 2008).

Second, GR critics often suggest that the right way to combat VAD will be to increase dietary diversity and rely on food naturally rich in vitamin A or $\beta$-carotene such as meat, liver, green leafy vegetables, orange-fleshed roots and tubers, red palm oil, or cod liver oil. Indeed, greater dietary diversity and more balanced food consumption are the most sustainable way to achieve nutritional security in the long term. However, each suggestion has to be analyzed in the particular context as in GR. For instance, red palm oil or cod liver oil are not typically consumed in India. These oils rather have to be considered medical supplement. Moreover, red palm oil cannot be directly consumed without utilizing special refinery technologies. For effective coverage of all 140 million children aged 6-59 months in India, about 245,000 tons of red palm oil would be needed. The area required for oil palm plantations would compete with other crops or potentially threaten biodiversity. Also, while studies on the red palm oil as a source of $\beta$-carotene in India dated as far back as 1936, the use of red palm oil is still not established in India. There certainly are nutritious foods for consumption, and further increase in their consumption will be desirable. However, relying on this path alone will not suffice. Meat is rich in vitamin A, but it is expensive. And, its promotion has certain limits in a society with customarily vegetarian populations. The $\beta$-carotene in some vegetables has poor bioavailability, and fresh produce is often only seasonally accessible and costly (Stein et al., 2008).

Third, home gardening, which is proposed as a means to ensure the availability of fruits and vegetables, might be possible in rural areas, but it may be improbable in populated areas factoring in costs and time to tend the garden (Stein et al., 2008). A study in Bangladesh demonstrated that technical assistance was required for home gardens to be effective in increasing vegetable consumption, and households needed a regular supply of quality seed and other inputs (Talukder et al., 2000). Additionally, human and institutional capacity may well be required to implement and monitor the program, and nutrition education to achieve behavioral changes (Stein et al., 2008).

\section{Conclusions}

To better understand the debate over GR, it is critical to acknowledge its multiple aspects and understand the core perspectives from the stakeholders. Some may have a genuine interest in humanity while others in political or economic gains. Also, promoting any potential benefits of GR should not ignore realistic irreversible harms, and the reverse is true as well; the real benefits from GR should not be cloaked in the political agenda of particular entities.

Critics of GE crops have identified GR as a symbol for GMOs released by multinational corporations solely for profits. However, that is not the case with GR. Moreover, the opponents and proponents do not seem to agree on roles that GR should play to lessen VAD. The intention of GR development is not to replace the existing effective interventions but to supplement them when possible. However, at the same time, GR should concretely show and prove its safety and efficacy with well-conducted studies. The article (Tang et al., 2012) retraction on grounds of research ethics, for instance, is bound to raise a level of public suspicion towards GR. Furthermore, the debate surrounding GR should be foremost science-based and public policy oriented. As one of its primary beneficiaries is children aged 6-59 months in developing countries, the debate seems often excessively emotional rather than science-based. Instead, valid, peer-reviewed studies on social and economic issues will offer either side a stronger voice, rather than gray media such as opinionated blogs or commentaries with little credible evidentiary support.

Finally, according to the IRRI and Golden Rice Project Network, GR will likely be the first transgenic biofortified rice to be released in the near future. Both GE technologies to develop crops and technologies to verify their safety have been rapidly advancing. Many would argue that national and international regulatory processes should not lag behind or be overly precautionary, so as not to obstruct a scientific breakthrough on behalf of human welfare. This was certainly the intent of the open letter by 109 Nobel Laureates who wrote: "We call upon Greenpeace to cease and desist in its campaign against Golden Rice specifically, and crops and foods improved through biotechnology in general" (Support 
Precision Agriculture, 2016 June 29). Although it is imprudent to relax rules with insufficient evidence for safety, authorities should avoid unnecessary bureaucratic burdens and equip themselves to discriminate against entities with vested self-interests and political agendas. On the other hand, the newly released U.S.A National Academies of Sciences, Engineering and Medicine report on GE crops recommends a complete omics (a complete molecular profile of the crop including DNA sequence, gene expression and molecular composition) analysis in order to insure that the genetic modification does not produce any unintended effects and validates substantial equivalence between the transgenic crop and non-GE or deregulated GE counterpart (NASEM, 2016).

The GR project has been both supported and criticized since its inception. This particular project, simultaneously reflects how the public perception on GE technology and its application have evolved but with some lessons. Thus, approval or disapproval and acceptance or rejection of GR in the near future can certainly describe the direction in which society is headed with respect to food and genetic technologies.

\section{Acknowledgements}

The authors thank Steven E. Ullrich at Department of Crop and Soil Sciences, Washington State University, Pullman, WA, U.S.A for his valuable reading and comments on the manuscript. The authors declare no conflicts of financial interests.

\section{Reference}

Abdullah, B., \& Villegas, V. N. (2015 February 16-17). Golden Rice Project: Indonesia-IRRI Workplan Meeting. IRRI. Retrieved from file:///C:/Users/SAMSUNG/Downloads/villegas-id-irri-wp\%20(2).pdf

Al-Babili, S., \& Beyer, P. (2005). Golden Rice-five years on the road-five years to go? Trends in plant science, 10(12), 565-573

American Journal of Clinical Nutrition. (2015). Retraction of Tang G, Hu Y, Yin S-a, Wang Y, Dallal GE, Grusak MA, and Russell RM. b-Carotene in Golden Rice is as good as b-carotene in oil at providing vitamin A to children. American Journal of Clinical Nutrition. doi:10.3945/ajen.114.093229

Barklund, A., \& Lindqvist, A. K. (2009). Golden rice and other biofortified food crops for developing countries: challenges and potential: report from the Bertebos Conference in Falkenberg, Sweden, 7-9 September 2008: Royal Swedish Academy of Agriculture and Forestry in coop. with the Bertebos Foundation.

Berman, J., Zhu, C., Pérez-Massot, E., Arjó, G., Zorrilla-López, U., Masip, G., . . Miralpeix, B. (2013). Can the world afford to ignore biotechnology solutions that address food insecurity? Plant molecular biology, 83(1-2), 5-19.

Beyer, P., Al-Babili, S., Ye, X., Lucca, P., Schaub, P., Welsch, R., \& Potrykus, I. (2002). Golden rice: Introducing the $\beta$-carotene biosynthesis pathway into rice endosperm by genetic engineering to defeat vitamin A deficiency. The Journal of nutrition, 132(3), 506S-510S.

Boileau, T. W. (1999). Carotenoids and vitamin A. Antioxidant Status, Diet, Nutrition and Health.

Brooks, S. (2013). Biofortification: lessons from the Golden Rice project. Food Chain, 3(1-2), 77-88.

Christensen, J. (2000 Nov 21). Golden rice in a grenade-proof greenhouse. New York Times. Retrieved from $\mathrm{http}: / / \mathrm{www}$. nytimes.com/2000/11/21/science/21RICE.html?pagewanted=all

Cotter, J. (2013 October). Golden Illusion: The Broken Promises of "Golden Rice." Retrieved from http://www.greenpeace.org/international/Global/international/publications/agriculture/2013/458\%20-\%20Gold en\%20Illusion-GE-goldenrice.pdf

Dash, S., Sahoo, K., Chattopadhyay, K., Behera, L., Pradhan, S., Molla, K., \& Mohapatra, S. (2016). High Beta-Carotene Rice in Asia: Techniques and Implications Biofortification of Food Crops (pp. 359-374): Springer.

De Moura, F. F., Miloff, A., \& Boy, E. (2015). Retention of provitamin A carotenoids in staple crops targeted for biofortification in Africa: cassava, maize and sweet potato. Critical reviews in food science and nutrition, 55(9), 1246-1269.

De Moura, F. F., Moursi, M., Angel, M. D., Angeles-Agdeppa, I., Atmarita, A., Gironella, G. M., . . Carriquiry, A. (2016). Biofortified $\beta$-carotene rice improves vitamin $A$ intake and reduces the prevalence of inadequacy among women and young children in a simulated analysis in Bangladesh, Indonesia, and the Philippines. The American journal of clinical nutrition, ajen129270.

De Steur, H., Blancquaert, D., Strobbe, S., Lambert, W., Gellynck, X., \& Van Der Straeten, D. (2015). Status and market potential of transgenic biofortified crops. Nature biotechnology, 33(1), 25-29. 
De Steur, H., Gellynck, X., Blancquaert, D., Lambert, W., Van Der Straeten, D., \& Qaim, M. (2012). Potential impact and cost-effectiveness of multi-biofortified rice in China. New Biotechnology, 29(3), 432-442.

De Steur, H., Mogendi, J. B., Blancquaert, D., Lambert, W., Van Der Straeten, D., \& Gellynck, X. (2014). Genetically modified rice with health benefits as a means to reduce micronutrient malnutrition: Global status, consumer preferences and potential health impacts of rice biofortification. London, UK: Elsevier Academic Press.

Deb, U. (2016). Returns to Golden Rice Research in Bangladesh: An Ex-ante Analysis. Copenhagen Consensus Center.

Deodhar, S. Y., Ganesh, S., \& Chern, W. S. (2008). Emerging markets for GM foods: A study of consumer's willingness to pay in India. Int J Biotechnol, 10(6), 570-587.

Department of Science and Technology-Biosafety Committee. (2015 Feb ). Approved Experiments Retrieved from http://dost-bc.dost.gov.ph/approved-experiments/details/1/47

Depositario, D. P. T., Nayga Jr, R. M., Wu, X., \& Laude, T. P. (2009). Effects of information on consumers' willingness to pay for golden rice. Asian Economic Journal, 23(4), 457-476.

Dubock, A. (2014). The politics of golden rice. GM crops \& food, 5(3), 210-222.

Enserink, M. (2013 September 18). Golden Rice Not So Golden for Tufts. Retrieved from http://www.sciencemag.org/news/2013/09/golden-rice-not-so-golden-tufts

Fischer, R., Byerlee, D., \& Edmeades, G. (2014). Crop yields and global food security. ACIAR: Canberra, ACT.

Gannon, B., Kaliwile, C., Arscott, S. A., Schmaelzle, S., Chileshe, J., Kalungwana, N., . . Tanumihardjo, S. A. (2014). Biofortified orange maize is as efficacious as a vitamin A supplement in Zambian children even in the presence of high liver reserves of vitamin A: a community-based, randomized placebo-controlled trial. Am J Clin Nutr, 100, 1541-1550.

Gayen, D., Ali, N., Sarkar, S. N., Datta, S. K., \& Datta, K. (2015). Down-regulation of lipoxygenase gene reduces degradation of carotenoids of golden rice during storage. Planta, 242(1), 353-363.

Golden Rice Humanitarian Board [GRHB]. (n.d. a). Who invented Golden Rice and how did the project start? Retrieved from http://www.goldenrice.org/Content3-Why/why3_FAQ.php\#Inventors

Greenpeace International. (2012 September 5). Greenpeace alarmed at US-backed GMO experiments on children. Retrieved from http://www.greenpeace.org/seasia/ph/press/releases/Greenpeace-alarmed-at-US-backed-GMO-experiments-onchildren/

GRHB. (n.d. b). Humanitarian Board Member Prof Ingo Potrykus. Retrieved from http://www.goldenrice.org/Content1-Who/who1_humbo.php

GRHB. (n.d. c). Golden Rice Humanitarian Board, Golden Rice and Intellectual Property. Retrieved from http://www.goldenrice.org/Content1-Who/who4_IP.php

Grusak, M. A. (2005). Golden Rice gets a boost from maize. Nature biotechnology, 23(4), 429-430.

Harjes, C. E., Rocheford, T. R., Bai, L., Brutnell, T. P., Kandianis, C. B., Sowinski, S. G., . . Wurtzel, E. T. (2008). Natural genetic variation in lycopene epsilon cyclase tapped for maize biofortification. Science, 319(5861), 330-333.

HarvestPlus. (2015 August 5). Bangladesh Releases New, Improved Zinc Rice Variety. Retrieved from http://www.harvestplus.org/knowledge-market/in-the-news/bangladesh-releases-new-improved-zinc-rice-variet $\mathrm{y}-0$

Hoa, T. T. C., Al-Babili, S., Schaub, P., Potrykus, I., \& Beyer, P. (2003). Golden Indica and Japonica rice lines amenable to deregulation. Plant physiology, 133(1), 161-169.

Hvistendahl, M., \& Enserink, M. (2012 September 11). Firestorm Erupts Over Transgenic Rice Study in Chinese Children. Retrieved from http://www.sciencemag.org/news/2012/09/firestorm-erupts-over-transgenic-rice-study-chinese-children

International Rice Research Institute [IRRI]. (n.d. a). What is the status of the Golden Rice project coordinated by IRRI? Retrieved from http://irri.org/golden-rice/faqs/what-is-the-status-of-the-golden-rice-project-coordinated-by-irri

IRRI. (n.d. b). Is Golden Rice safe? Retrieved from http://irri.org/golden-rice/faqs/is-golden-rice-safe

Kajale, D. B., \& Becker, T. C. (2015). Willingness to Pay for Golden Rice in India: A Contingent Valuation Method Analysis. Journal of Food Products Marketing, 21(4), 319-336. 
Kowalski, S. P. (2015). Golden Rice, Open Innovation, and Sustainable Global Food Security. Industrial Biotechnology, 11(2), 84-90.

Kowalski, S. P., \& Kryder, R. D. (2002). Golden rice: a case study in intellectual property management and international capacity building. Risk, 13, 47.

Krawinkel, M. B. (2007). What we know and don't know about Golden Rice. Nature biotechnology, 25(6), 623-623.

Lusk, J. L. (2003). Effects of cheap talk on consumer willingness-to-pay for golden rice. American Journal of Agricultural Economics, 85(4), 840-856.

Lusk, J. L., Jamal, M., Kurlander, L., Roucan, M., \& Taulman, L. (2005). A meta-analysis of genetically modified food valuation studies. Journal of Agricultural and Resource Economics, 28-44.

Marseille, E., Larson, B., Kazi, D. S., Kahn, J. G., \& Rosen, S. (2015). Thresholds for the cost-effectiveness of interventions: alternative approaches. Bulletin of the World Health Organization, 93(2), 118-124.

Miller, H. I., \& Kershen, D. L. (2013). Politics and the poor man's plate. Defining Ideas, January, 10.

Murray, C. J., \& Lopez, A. D. (1996). Global burden of disease (Vol. 1): Harvard University Press Cambridge, MA.

Nash, J. M., Zurich Monday, J., \& Potrykus, I. (2000 July). This rice could save a million kids a year. TIME Magazine 31.

National Academies of Sciences Engineering and Medicine [NASEM]. (2016). Genetically Engineered Crops: Experiences and Prospects. Retrieved from Washington, DC:

Novotny, J. A., Harrison, D. J., Pawlosky, R., Flanagan, V. P., Harrison, E. H., \& Kurilich, A. C. (2010). $\beta$-Carotene conversion to vitamin A decreases as the dietary dose increases in humans. The Journal of nutrition, 140(5), 915-918.

Onyango, B. M., \& Nayga Jr, R. M. (2004). Consumer acceptance of nutritionally enhanced genetically modified food: relevance of gene transfer technology. Journal of Agricultural and Resource Economics, 567-583.

Paine, J. A., Shipton, C. A., Chaggar, S., Howells, R. M., Kennedy, M. J., Vernon, G., . . Silverstone, A. L. (2005). Improving the nutritional value of Golden Rice through increased pro-vitamin A content. Nature biotechnology, 23(4), 482-487.

Potrykus, I. (2001). Golden rice and beyond. Plant physiology, 125(3), 1157-1161.

Potrykus, I. (2010). Lessons from the 'Humanitarian Golden Rice'project: Regulation prevents development of public good genetically engineered crop products. New Biotechnology, 27(5), 466-472.

Privalle, L. S. (2002). Phosphomannose isomerase, a novel plant selection system. Annals of the New York Academy of Sciences, 964(1), 129-138.

Prom - u - thai, C., Rerkasem, B., Fukai, S., \& Huang, L. (2009). Iron fortification and parboiled rice quality: appearance, cooking quality and sensory attributes. Journal of the Science of Food and Agriculture, 89(15), 2565-2571.

Schubert, D. R. (2008). The problem with nutritionally enhanced plants. Journal of medicinal food, 11(4), 601-605.

Shimelis, H., \& Laing, M. (2012). Timelines in conventional crop improvement: pre-breeding and breeding procedures. Australian Journal of Crop Science, 6(11), 1542.

Siegrist, M. (2008). Factors influencing public acceptance of innovative food technologies and products. Trends in Food Science \& Technology, 19(11), 603-608.

Stein, A. J., Sachdev, H., \& Qaim, M. (2006). Potential impact and cost-effectiveness of Golden Rice. Nature biotechnology, 24(10), 1200-1201.

Stein, A. J., Sachdev, H., \& Qaim, M. (2008). Genetic engineering for the poor: Golden Rice and public health in India. World Development, 36(1), 144-158.

Stephensen, C. B. (2001). Vitamin A, infection, and immune function. Annual review of nutrition, 21(1), 167-192.

Stevens, G. A., Bennett, J. E., Hennocq, Q., Lu, Y., De-Regil, L. M., Rogers, L., . . Flaxman, S. R. (2015). Trends and mortality effects of vitamin A deficiency in children in 138 low-income and middle-income countries between 1991 and 2013: a pooled analysis of population-based surveys. The Lancet Global Health, 3(9), e528-e536.

Stevens, R., \& Winter-Nelson, A. (2008). Consumer acceptance of provitamin A-biofortified maize in Maputo, Mozambique. Food Policy, 33(4), 341-351. 
Support Precision Agriculture. (2016 June 29). Laureates Letter Supporting Precision Agriculture (GMOs). Retrieved from http://supportprecisionagriculture.org/nobel-laureate-gmo-letter_rjr.html

Talukder, A., Kiess, L., Huq, N., de Pee, S., Darnton-Hill, I., \& Bloem, M. W. (2000). Increasing the Production and Consumption of Vitamin A-Rich Fruits and Vegetables: Lessons Learned in Taking the Bangladesh Homestead Gardening Programme to a National Scale. Food and Nutrition Bulletin, 21(2), 165-172.

Tang, G., Hu, Y., Yin, S., Wang, Y., Dallal, G., Grusak, M., \& Russell, R. (2009). Golden Rice is an effective source of vitamin A. The American journal of clinical nutrition, 89(6), 1776-1783.

Tang, G., Hu, Y., Yin, S., Wang, Y., Dallal, G., Grusak, M., \& Russell, R. (2012). $\beta$-Carotene in Golden Rice is as good as $\beta$-carotene in oil at providing vitamin A to children. The American journal of clinical nutrition, 96(3), 658-664.

Tanumihardjo, S. A., Mokhtar, N., Haskell, M. J., \& Brown, K. H. (2016). Assessing the Safety of Vitamin A Delivered Through Large-Scale Intervention Programs Workshop Report on Setting the Research Agenda. Food and Nutrition Bulletin, 37(2 suppl), S63-S74.

United Nations Children's Fund. (2016). Vitamin A Supplementation: A Statistical Snapshot. Retrieved from http://data.unicef.org/resources/vitamin-supplementation-statistical-snapshot/

Walker, C. L. F., Rudan, I., Liu, L., Nair, H., Theodoratou, E., Bhutta, Z. A., . . Black, R. E. (2013). Global burden of childhood pneumonia and diarrhoea. The Lancet, 381(9875), 1405-1416. doi:http://dx.doi.org/10.1016/S0140-6736(13)60222-6

Waltz, E. (2010). China's GM rice first. Nature biotechnology, 28(1), 8-8.

Wambugu, F., Obukosia, S., Gaffney, J., Kamanga, D., Che, P., Albertsen, M. C., . . Kimani, E. (2015). Is there a place for nutrition-sensitive agriculture? Proceedings of the Nutrition Society, 74(04), 441-448.

Wesseler, J., \& Zilberman, D. (2014). The economic power of the Golden Rice opposition. Environment and Development Economics, 19(06), 724-742.

World Health Organization. (2011). Guideline: vitamin A supplementation in infants and children 6-59 months of age (9241501766). Retrieved from Geneva:

Ye, X., Al-Babili, S., Klöti, A., Zhang, J., Lucca, P., Beyer, P., \& Potrykus, I. (2000). Engineering the provitamin A ( $\beta$-carotene) biosynthetic pathway into (carotenoid-free) rice endosperm. Science, 287(5451), 303-305.

Zilberman, D., \& Wesseler, J. (2014). The impacts and acceptance of agricultural biotechnology: an introduction to the special issue. Environment and Development Economics, 19(06), 669-675.

\section{(c) $)_{\text {EY }}$}

This work is licensed under a Creative Commons Attribution 3.0 License. 